\title{
Taxas longitudinais de diplomação, evasão e trancamento: método para análise da trajetória discente na educação superior
}

\author{
Longitudinal rates of completion, drop-out and leave of absence: \\ method for analyzing the student trajectory in higher education
}

\author{
Maria Daniele de Jesus Teixeira ${ }^{1}$ \\ Fábio de Moraes Quito ${ }^{2}$
}

Resumo: Diante da necessidade de conhecer a realidade das instituições de ensino superior, foram desenvolvidos uma multiplicidade de índices acadêmicos com diversas metodologias. No entanto, nota-se escassez de métodos que descrevam com detalhes a trajetória de discentes com múltiplos períodos de ingresso. Neste sentido, este artigo tem como objetivo sistematizar e aplicar uma metodologia para analisar a trajetória longitudinal das turmas no que tange à diplomação, evasão e trancamento, de acordo com ano de ingresso e o prazo de integralização dos cursos no decorrer de 10 anos (2008 a 2017). Para tal, algumas metodologias de fluxo foram adaptadas, dividindo as turmas por ano de ingresso e padronizando o período de integralização. Os resultados permitem analisar a trajetória dos discentes no período mínimo e máximo de integralização, assim como comparar os valores com taxas já publicadas, possibilitando maior conhecimento da realidade, disponibilizando instrumentos mais adequados para balizar o planejamento de políticas de desenvolvimento institucional.

Palavras-chave: Método. Indicadores acadêmicos. Prazo de integralização. 
Abstract: Faced with the need to know the reality of higher education institutions, a multiplicity of academic indexes was developed with different methodologies. However, there is a scarcity of methods that describe in detail the trajectory of students with multiple enrollment periods. The data analyzed in a longitudinal way has the potential to demonstrate more the reality of the university, although it is laborious to calculate. In this sense, this article aims to systematize and apply a methodology to analyze the longitudinal trajectory of the students with respect to completion, drop-out and leave of absence, according to the year of entry and the term of completion of the courses over 10 years (2008 to 2017). To this end, some flow methodologies have been adapted, dividing the classes by year of entry, and standardizing the period of completion. The results allow to analyze the trajectory of the students in the minimum and maximum period of completion, as well as to compare the values with rates already published, allowing greater knowledge of the reality, providing more adequate instruments to guide the planning of institutional development policies.

Keywords: Method. Academic indicators. Completion term.

${ }^{1}$ Universidade Federal de Mato Grosso| Programa de Pós-Graduação em Economia | Cuiabá | MT | Brasil. Contato: danieleufmt@gmail.com. ORCID: http://orcid.org/0000-0001-5240-2739

${ }^{2}$ Universidade Federal de Mato Grosso | Programa de Pós-Graduação em Economia | Cuiabá | MT | Brasil. Contato: fabioquito@gmail.com. ORCID: https://orcid.org/0000-0003-1095-5663

- Recebido em: 19 de janeiro de 2021

- Aprovado em: 12 de maio de 2021

DOI: http://dx.doi.org/10.1590/S1414-40772021000200011

Este é um artigo publicado em acesso aberto sob uma licença Creative Commons https://creativecommons.org/licenses/by-nc/4.0/ 


\section{Introdução}

A democratização do acesso à educação superior, com a garantia de manutenção da qualidade, é um dos compromissos do Estado brasileiro, conforme citado na meta 12 do Plano Nacional de Educação 2014-2024 (BRASIL, 2014). Neste sentido, nota-se que as universidades brasileiras têm vivenciado uma grande expansão como resultado de políticas governamentais de incentivo à expansão da rede privada e do Programa de Apoio a Planos de Reestruturação e Expansão das Universidades Federais (Reuni), iniciado em 2007 (SANTOS JUNIOR; REAL, 2017). No entanto, ampliar o acesso não é suficiente, se não vier acompanhado das condições que contribuam para a permanência dos estudantes, do ingresso à formatura. É nesse contexto que a análise aprofundada da evasão e retenção se torna peça-chave no intricado painel de fenômenos que cercam a educação superior.

Apesar do conhecimento das inúmeras razões apontadas pela literatura científica para a evasão estudantil (SILVA FILHO et al., 2007; BAGGI; LOPES, 2011; SANTOS JUNIOR; REAL, 2017; DURSO; CUNHA, 2018), esse fenômeno, que traz prejuízos tanto para o estudante quanto para a instituição, tem-se intensificado nos últimos anos.

Os dados publicados pelo Instituto Nacional de Estudos e Pesquisas Educacionais Anísio Teixeira (INEP, 2018), órgão responsável pelo Censo da Educação Superior, mostram que entre os anos de 2010 e 2017 houve um incremento de aproximadamente 40\% no número de estudantes desvinculados de cursos de graduação presencial. Enquanto por outro lado, para o mesmo período, o quantitativo de estudantes formados aumentou menos de 15\%. Esses dados demonstram a complementariedade existente entre evasão e diplomação, tendo a retenção como um evento que pode expor as dificuldades enfrentadas pelo estudante, culminando com prolongamento da vida acadêmica do estudante.

Vários estudos apontam que há uma lacuna em torno do que define e mensura a evasão estudantil (CUNHA; TUNES; SILVA, 2001; SILVA FILHO; LOBO, 2012; SANTOS JUNIOR; REAL, 2017). Para Cunha, Tunes e Silva (2001), falta um consenso na literatura sobre como entender ou medir a evasão no ensino superior por meio de uma metodologia que permita delimitar com precisão os seus índices. Como exemplo, cita-se vários métodos para determinar o índice de evasão de uma instituição, dentre estes, alguns autores utilizam dados agregados (VELOSO; ALMEIDA, 2001; SILVA FILHO et al. ,2007), outros utilizam dados individuais de acordo com o período de ingresso tanto para realizar uma análise longitudinal (MASSI; VILLANI, 2015; SOUZA, 2014; CABELLO et al., 2018) quanto para uma abordagem por meio de modelos probabilísticos (GERAB, 2016). Neste sentido, é fundamental 
a discussão e comparação das metodologias de alguns indicadores existentes, analisando as possibilidades e limitações destes para o monitoramento da trajetória discente.

Partindo dessa análise, a pesquisa tem o objetivo de sistematizar e aplicar uma metodologia de análise da trajetória acadêmica dos estudantes na qual serão apresentados três indicadores alternativos, de caráter longitudinal, para acompanhar as trajetórias dos estudantes de graduação, aqui denominados de Taxa Longitudinal de Evasão (TLE), Taxa Longitudinal de Diplomação (TLD) e Taxa Longitudinal de Trancamento (TLT). Desta forma, pretende-se também contrapor os resultados com as taxas existentes, como exemplo a Taxa de Sucesso na Graduação exigida pelo Tribunal de Contas da União (TSG-TCU) no Relatório de Gestão elaborado pelas instituições federais de ensino, descrevendo os limites e vantagens da utilização de cada método.

Os indicadores foram elaborados com dados extraídos do registro acadêmico dos estudantes da Universidade Federal de Mato Grosso, levando em consideração o ano de ingresso e o prazo de integralização. Posteriormente, utilizou-se de agregação por tabelas dinâmicas e gráficos para descrever as situações dos discentes ao longo de seu percurso na universidade, possibilitando maior conhecimento da realidade institucional, assim como, dos instrumentos mais adequados para balizar o planejamento de políticas de desenvolvimento institucional.

\section{Acesso, retenção e evasão na educação superior}

Fundamentado pelo diagnóstico de que o ensino superior brasileiro era destinado às classes com maior poder aquisitivo iniciou-se, no começo dos anos 2000, um processo de expansão e democratização do acesso ao ensino superior. Esse processo ocorreu com a implementação de políticas voltadas para o setor público e privado. No âmbito privado, foram criados o Fundo de Financiamento Estudantil (FIES) e o Programa Universidade para Todos (PROUNI), enquanto que no segmento público a principal política foi aumentar o número de vagas, criar e ampliar o alcance das universidades federais por meio do Programa de Apoio a Planos de Reestruturação e Expansão das Universidades Federais (REUNI) (SANTOS JUNIOR; REAL, 2017).

Entretanto, o acesso à universidade implica em outros tipos de acesso, quer dizer, que o ingresso por si só não garante a continuidade ou término do curso de graduação, sendo necessário "considerar a dimensão de permanência, que sinaliza o percurso sequente e bemsucedido" (SILVA; VELOSO, 2013, p. 730), é neste contexto que o fenômeno da evasão ganha 
dimensões até então desconhecidas no sistema de educação superior. Existem inúmeras situações registradas na trajetória do discente, estas podem variar dependendo da categoria administrativa da instituição, porém, de forma geral, estão relacionadas às possibilidades evidenciadas na Figura 1.

Figura 1 - Possibilidades de situação (status) de matrícula dos discentes

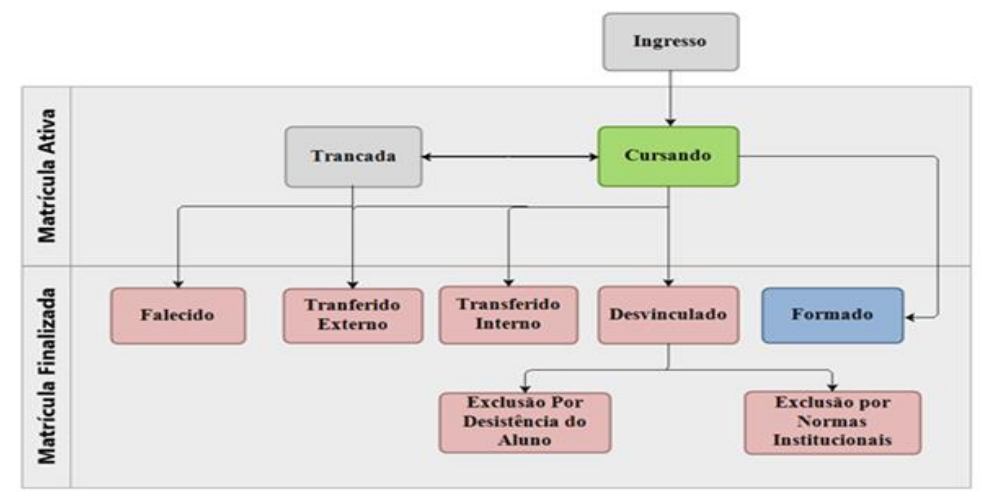

Fonte: Elaboração própria (2020).

A Figura 1 evidencia as situações possíveis na trajetória que o aluno pode percorrer até sua saída do curso. Essa saída pode ser com "êxito", quando a matrícula é finalizada com a situação de "Formado" ou sem êxito, quando ocorre sua desvinculação do curso, que pode ocorrer por solicitação do estudante ou por decisão fundamentada em normas da instituição de ensino. Além disso, em seu percurso acadêmico diversos fatores, pessoais ou institucionais, podem aumentar o tempo de vínculo do estudante com a instituição, postergando, assim, sua finalização de matrícula (retenção).

Além dos múltiplos procedimentos e dispositivos complexos utilizados para diminuir a evasão, considerando seu aspecto heterogêneo, a literatura tem diferentes abordagens para definir o tema. Para Gaioso (2005), evasão é definida como toda e qualquer interrupção no ciclo de estudos. Entretanto, alguns autores acreditam que a evasão constatada apenas na perspectiva do curso pode não ser considerado um fator de insucesso, pois pode evidenciar um período de transição do estudante para um curso no qual possua mais afinidade, conforme aponta Ristoff (1999, p. 125): "parcela significativa do que chamamos de evasão, no entanto, não é exclusão mas mobilidade, não é fuga [...] mas tentativa de buscar o sucesso ou a felicidade, aproveitando as revelações que o processo natural de crescimento do indivíduo faz sobre suas reais potencialidades". Contudo, essa visão de que a evasão possa se tornar uma etapa do desenvolvimento pessoal é confrontada, atualmente, com os recursos alocados e desperdiçados 
no ensino superior. A dificuldade no diagnóstico e na definição de políticas voltadas ao combate da evasão está relacionada, principalmente, ao seu caráter multifacetado e ao poder de impacto dessas políticas, posto que algumas dessas causas podem estar associadas ao aspecto pessoal do estudante.

A Comissão Especial de Estudos sobre a Evasão nas Universidades Públicas Brasileiras (BRASIL, 1997) define três tipos de evasão: 1) do curso - relacionada ao desligamento do curso quando o aluno deixa de se matricular em disciplinas (abandono), desistência oficial, transferência, mudança de curso e exclusão por norma institucional; 2) da instituição relacionada ao desligamento da instituição mas permanência no sistema; e 3) do sistema de ensino superior - relacionada ao abandono definitivo ou temporário do ensino superior. Comumente os estudos abordam apenas dois tipos de evasão previstos: a do curso, também chamada de evasão aparente, e do sistema ou evasão real (POLYDORO, 2000; CARDOSO, 2008). Neste estudo abordaremos a evasão do curso, considerando a situação de "desvinculado", podendo tanto ocorrer por desistência do aluno quanto por determinação da instituição.

\section{Indicadores e a educação superior}

Indicadores são números que servem como medidas utilizadas nas mais diversas situações e campos do conhecimento, cuja função principal é traduzir em métricas resumidas fenômenos muito mais complexos. No contexto acadêmico, "os indicadores proporcionam a revelação de aspectos significativos para a melhoria contínua do processo educacional, fornecendo informações relevantes sobre a realidade." (CAVALCANTE, 2011, p. 47), constituindo-se em um processo permanente, participativo, capaz de mapear as potencialidades e fragilidades da instituição.

Nas universidades federais esses instrumentos fazem parte do cotidiano estando largamente difundidos nos setores administrativos. Em 2002, o Tribunal de Contas da União (TCU, 2010) determinou que as universidades federais elaborassem nove indicadores de desempenho para aprimorar a gestão dessas instituições, de acordo com Silva, Morgan e Costa (2004) esses instrumentos foram desenvolvidos a partir de auditorias efetuadas em diversas universidades federais. Além disso, o Ministério da Educação desenvolveu, em 2004, o Sistema Nacional de Avaliação da Educação Superior (SINAES), que é composto por três avaliações: de instituições, de cursos e de desempenho dos estudantes (FREIRE; CRISÓSTOMO; CASTRO, 2007). 
Dentre os indicadores impostos pelo TCU às instituições federais de ensino, destaca-se a Taxa de Sucesso na Graduação (TSG). Ela é determinada pelo número de diplomados de um ano em relação ao número de ingressantes de quatro, cinco ou seis anos anteriores, a depender do tempo de integralização do curso, ou seja, mede o percentual de ingressantes que concluíram o curso dentro do prazo mínimo de integralização, e de forma complementar, o índice de evasão. O Instituto Nacional de Estudos e Pesquisas Educacionais Anísio Teixeira (INEP, 2017) também sugere outros métodos de cálculo de algumas taxas, que serão mais bem detalhadas na metodologia. Alguns autores tecem críticas aos instrumentos desenvolvidos pelo TCU, no sentido de eles estarem mais preocupados em medir os custos financeiros do que "mensurar o retorno da universidade para a sociedade e para o indivíduo" (SILVA; MORGAN; COSTA, 2004, p. 245). Ao propor seus indicadores longitudinais, Lima Junior et al. (2019) expõe que a TSG, em alguns casos, confunde mobilidade com evasão, desconsidera a necessidade de retenção na trajetória acadêmica.

Destaca-se também os indicadores educacionais descritos em INEP (2017), estes usualmente subsidiam discussões acerca da eficácia do sistema de ensino superior, principalmente quanto à capacidade deste para produzir concluintes. Descrevem desta forma, alguns indicadores diretos, sistematizados em uma trajetória cronológica e materializada a partir do vínculo discente com o respectivo curso, abrangem três grandes condições de vínculo do discente com o sistema de ensino superior: permanência, desistência e conclusão.

\section{Método}

A presente pesquisa caracteriza-se como exploratória e descritiva, com abordagem quantitativa. Foram considerados os ingressantes dos cursos de graduação presencial da UFMT de 2008 a 2017, aproximadamente 54.000 discentes. Nesse período, alguns dos alunos não atingiram o prazo mínimo de integralização de seus cursos, neste sentido, não há de se falar em evasão, entretanto, é possível identificar alguns padrões que possam levar a essa situação, viabilizando ações de acompanhamento e de prevenção. Desconsiderou-se os alunos matriculados em cursos à distância, pois o caso da educação a distância deve ser tratado de forma específica, considerando sua natureza diferenciada.

Para sistematizar e aplicar a metodologia para analisar a trajetória longitudinal das turmas foram adaptadas algumas metodologias de fluxo, dentre elas INEP (2017), Pereira, Zavala e Santos (2011) e Souza (2014). Considerou-se as seguintes situações: formado (Trajetória Longitudinal de Diplomação - TLD), desvinculado do curso (Trajetória 
Longitudinal de Evasão - TLE) e matrícula trancada (Trajetória Longitudinal de Trancamento - TLT). Cabe ressaltar que as duas primeiras taxas são acumulativas, uma vez que elas implicam a saída definitiva do estudante, com ou sem diploma. Por outro lado, para a TLT existe a possibilidade de retorno do estudante à atividade acadêmica ou da renovação de seu trancamento de matrícula em anos subsequentes, dessa forma funcionando com um indicador de retenção. Os gráficos e tabelas foram organizados de forma que possibilite analisar as turmas desde seu primeiro ano no curso até o décimo ano (quando disponível).

\subsection{Construção da coorte de estudantes}

Para possibilitar analisar de forma detalhada a trajetória dos discentes por ano de ingresso na UFMT foram necessárias algumas etapas, tendo em vista a necessidade de uma abordagem tanto geral quanto detalhada, que representasse a realidade da Universidade.

Inicialmente procedeu-se a análise do banco de dados. Este foi extraído do Sistema Acadêmico da UFMT (SIGA) em agosto de 2018. A extração foi feita pela Gerência de Estatística e Informações Institucionais da pró-reitoria de planejamento (GEII/PROPLAN), levando em consideração as metodologias utilizadas no Censo da Educação Superior/MEC/INEP. Após, foram realizadas adequações, dentre estas, destaca-se a necessidade de anualizar as informações que eram semestrais e, para evitar duplicidade, filtrouse a última situação do discente no ano em questão. Posteriormente, foram retirados cursos com oferta não regular e prazo de integralização fora dos padrões, a exemplo, os cursos do Plano Nacional de Formação de Professores da Educação Básica (PARFOR).

Diante do grande volume de informações, algumas foram ajustadas para possibilitar uma análise linear, como exemplo, estabelecer períodos padronizados de integralização, conforme evidenciado na Tabela 1. Esta etapa tornou-se necessária, uma vez que os dados dos estudantes, conforme foi relatado, foram anualizados.

Tabela 1 - Método de ajuste nos prazos mínimos e máximos de integralização.

\begin{tabular}{c|c|c}
\hline Prazo de Integralização (anos) & Período Mínimo ajustado* (anos) & Período Máximo ajustado* (anos) \\
\hline 4 & 4 & 6 \\
\hline 4,5 & 5 & 8 \\
\hline 5 & 5 & 8 \\
\hline 6 & 6 & 9 \\
\hline
\end{tabular}

Fonte: Elaboração própria (2019).

* O período mínimo ajustado corresponde ao prazo de integralização do curso, quando não inteiro, arredondado para cima. O período máximo ajustado foi acrescentado mais 50\% do tempo, conforme Resolução 66/2009 do Conselho de Ensino, Pesquisa e Extensão (CONSEPE). 
Posteriormente, algumas informações foram organizadas para identificar cada turma de discentes ingressantes, para tal, utilizou-se o recurso de tabela dinâmica do Microsoft Excel, versão 2016. O código e-Mec e ano de ingresso foram organizados verticalmente, e o ano corrente, horizontalmente. Após, as turmas foram agregadas conforme o período de integralização, não de acordo com o ano corrente, como é mais usual, este foi um ponto crucial do método.

\subsection{Cálculo das taxas longitudinais}

Nas tabelas e gráficos elaborados, as análises de trajetória podem ou não expressar índices acumulativos. Dessa forma, na trajetória simples o índice refere-se ao período informado, enquanto na trajetória acumulada a taxa reflete o somatório de todos os índices até aquele período.

Para possibilitar análise mais simplificada, diante da grande quantidade de taxas, utilizou-se também da média aritmética ponderada. Esta é bastante similar à média aritmética comum, a diferença, é que na média aritmética todos os valores contribuem com peso igual, enquanto no cálculo da média aritmética ponderada leva em consideração a contribuição (peso) de cada termo.

O procedimento utilizado foi análise longitudinal de alunos ingressantes (divididos por turma, definida pelo ano de ingresso) nos anos de 2008 a 2017. Seguindo as fórmulas descritas de (1) a (3).

1) Trajetória Longitudinal de Diplomação (TLD)

$$
\begin{aligned}
& T L D \_M i ́ n_{i, n, p}=\frac{\sum_{i=2008}^{n^{p}} F_{0 r} r_{T, n, p}}{I n g_{i=T}^{n}} x 100 \\
& T L D \_M a ́ x_{i, n, p}=\frac{\sum_{i=2008}^{n^{1,5 p}} \text { For }_{T, n, p}}{\operatorname{Ing}_{i=T}^{n}} x 100
\end{aligned}
$$

Onde:

$T L D_{-} M i n_{i, n, p}$ : Trajetória de diplomação no prazo de integralização padrão da turma “ $T$ ”, no ano corrente "n" e no prazo de integralização "p".

TLD_Máx $x_{i, n, p}$ : Trajetória de diplomação no prazo de integralização máximo, da turma “ $T$ ”, no ano corrente "n" e no prazo de integralização "p".

$F_{T, n, p}$ : Número de discentes com situação de vínculo igual a "Formado" da turma T, no ano n, no prazo de integralização "p". (2008 a 2017) 
Ing $g_{i=T}^{n}$ : Número de discentes ingressantes na turma $\mathrm{T}$ (2008 a 2017)

2) Trajetória Longitudinal de Evasão (TLE)

$$
\begin{aligned}
& \operatorname{TrajEvaMín}_{i, n, p}=\frac{\sum_{i=2008}^{n^{p}} \operatorname{Eva}_{T, n, p}}{\operatorname{In} g_{i=T}^{n}} \times 100 \\
& \operatorname{TrajEvaMáx}_{i, n, p}=\frac{\sum_{i=2008}^{n^{1,5}} E v a_{T, n, p}}{\operatorname{In} g_{i=T}^{n}} \times 100
\end{aligned}
$$

Onde:

$T L E_{\_} M n_{i, n, p}$ : Trajetória de evasão no prazo de integralização mínimo da turma “ $T$ ”, no ano corrente "n" e no prazo de integralização "p".

$T L E_{\_} M a ́ x_{i, n, p}$ : Trajetória de evasão no prazo de integralização máximo, da turma “ $T$ ”, no ano corrente "n" e no prazo de integralização "p".

$E v a_{T, n, p}$ : Número de discentes com situação de vínculo igual a "Desvinculado" da turma T, no ano n, no prazo de integralização "p". (2008 a 2017)

$$
\operatorname{Ing}_{i=T}^{n} \text { : Número de discentes ingressantes na turma } \mathrm{T} \text { (2008 a 2017). }
$$

3) Trajetória Longitudinal de Trancamento (TLT)

$$
\begin{aligned}
& T L T_{-} M{ }_{i} n_{i, n, p}=\frac{\sum_{i=2008}^{n^{p}} \operatorname{Tranc}_{T, n, p}}{I n g_{i=T}^{n}} x 100 \\
& T L T_{-} M a ́ x_{i, n, p}=\frac{\sum_{i=2008}^{n^{1,5 p}} \operatorname{Tranc}_{T, n, p}}{\operatorname{Ing}_{i=T}^{n}} x 100
\end{aligned}
$$

Onde:

$T L T_{-} M i n_{i, n, p}$ : Trajetória de Trancamento no ano de integralização mínimo da turma " $T$ ”, no ano corrente "n" e no prazo de integralização "p".

$T L T_{\_} M a ́ x_{i, n, p}$ : Trajetória de evasão no ano de integralização máximo, da turma " $T$ ”, no ano corrente "n" e no prazo de integralização "p".

$\operatorname{Tranc}_{T, n, p}$ : Número de discentes com situação de vínculo igual a "Trancado" da turma T, no ano n, no ano de integralização "p". (2008 a 2017)

$\operatorname{Ing}_{i=T}^{n}$ : Número de discentes ingressantes na turma $\mathrm{T}$ (2008 a 2017).

\subsection{Cálculo de taxas e indicadores educacionais publicados}

Para facilitar a compreensão das diferentes taxas existentes, elaborou-se quadros com as principais informações, assim como a fórmula de cálculo e fonte. Desta forma, os Quadros 1, 2 e 3 descrevem o nome, a sigla, o objetivo, a fórmula de cálculo entre outras especificidades das taxas que serão utilizadas na comparação dos resultados. 
Quadro 1 - Descrição da Taxa de Sucesso na Graduação do TCU (TSG-TCU)

\begin{tabular}{|c|c|}
\hline Detalhamento & Descrição \\
\hline Nome/Sigla & Taxa de Sucesso (TSG) \\
\hline Objeto de mensuração & $\begin{array}{l}\text { Percentual do somatório de número de estudantes que se formaram no curso } j \text { no } \\
\text { ano } t \text { (todos concluintes no ano t) de integralização padrão desse curso } j \text { em } \\
\text { relação ao número de ingressantes i do curso } j \text { no ano } T \text { de ingresso. }\end{array}$ \\
\hline Fórmula de Cálculo & 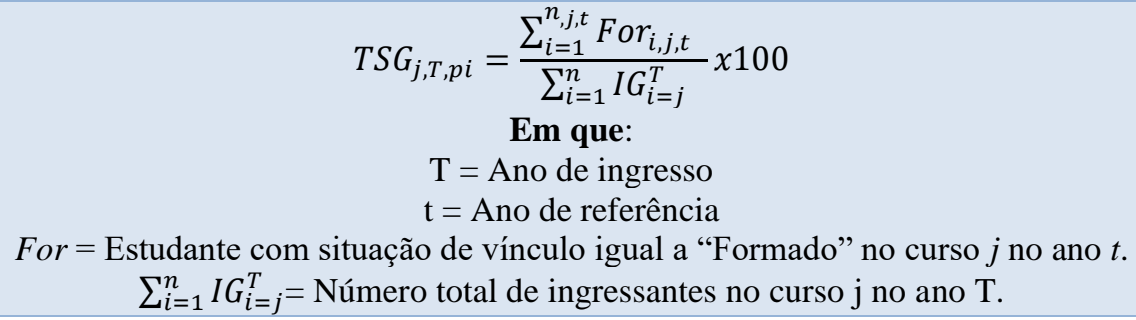 \\
\hline Unidade de medida & Porcentagem \\
\hline Periodicidade & Anual \\
\hline Intepretação & $\begin{array}{l}\text { Percentual de estudantes que se formam no período de integralização mínimo, } \\
\text { considerando todos os concluintes do ano dividido por todos ingressantes do ano } \\
\text { em questão. Quando todos os concluintes do ano são somados pode haver } \\
\text { concluintes que ingressaram em outros anos, diferentes de T. }\end{array}$ \\
\hline
\end{tabular}

Fonte: Adaptado de TCU (2010).

Quadro 2 - Descrição da Taxa de Eficiência do INEP (TEF-INEP)

\begin{tabular}{|c|c|}
\hline Detalhamento & Descrição \\
\hline Nome/Sigla & Taxa de Eficiência (TEF-INEP) \\
\hline Objeto de mensuração & $\begin{array}{l}\text { Percentual do número de estudantes que se formaram no curso } j \text { até o prazo de } \\
\text { integralização } p i \text { do curso } j \text { em relação ao número de ingressantes do curso } j \text { no } \\
\text { ano } T \text {, subtraindo-se o número de estudantes falecidos do curso } j \text { até o período pi }\end{array}$ \\
\hline Fórmula de Cálculo & $\begin{array}{c}T E F_{j, T, p i}=\frac{\sum_{w=T}^{t^{p i}} \sum_{i=1}^{n_{5, j, w}} F_{o r} r_{i, j, p i}}{\sum_{i=1}^{n} I G_{i=j}^{T}-\sum_{w=T}^{t} \sum_{i=1}^{n_{6, j, t}} F_{a l}} x 100 \\
\text { Em que: } \\
F a l=\text { Estudante com situação de vínculo igual a "Falecido" no curso } j \text { no ano } t . \\
\sum_{i=1}^{n} I G_{i=j}^{T}=\text { Número total de ingressantes no curso j no ano T }\end{array}$ \\
\hline Unidade de medida & Porcentagem \\
\hline Periodicidade & Anual \\
\hline Fonte & Fórmula do INEP aplicado a dados do SIGA. \\
\hline Intepretação & $\begin{array}{c}\text { Percentual do número de estudantes que se formaram em determinado curso até o } \\
\text { prazo de integralização mínima deste mais } 0,5 \text { ano ou mais } 1 \text { (um) Ano (a } \\
\text { depender se o período de integralização mínima é fracionado ou inteiro, } \\
\text { respectivamente) em relação ao número de ingressantes desse curso no ano de } \\
\text { ingresso considerado, subtraindo-se o número de estudantes falecidos nesse } \\
\text { período. }\end{array}$ \\
\hline
\end{tabular}

Fonte: Adaptado de INEP (2017).

Quadro 3 - Descrição da Taxa de Sucesso do INEP (TAS-INEP)

\begin{tabular}{|c|c|}
\hline Detalhamento & Descrição \\
\hline Nome/Sigla & Taxa de Sucesso (TAS-INEP) \\
\hline Objeto de mensuração & $\begin{array}{c}\text { Percentual do número de estudantes que se formaram no curso } j \text { até o final do } \\
\text { prazo de acompanhamento } p a \text { do curso } j \text {, em relação ao número de ingressantes } \\
\text { do curso } j \text { no ano } T, \text { subtraindo-se o número de estudantes falecidos do curso } j \text { até } \\
\text { o final do prazo de acompanhamento } p a .\end{array}$ \\
\hline
\end{tabular}




\begin{tabular}{|c|c|}
\hline Fórmula de Cálculo & $\begin{array}{c}T A S_{j, T, p}=\frac{\sum_{w=T}^{t} \sum_{i=1}^{n_{5, j, w}} F_{o r} r_{i, j, p a}}{\sum_{i=1}^{n} I G_{i=j}^{T}-\sum_{w=T}^{t} \sum_{i=1}^{n_{6, j, t}} F_{a l, j, t}} x 100 \\
\text { Em que: } \\
F o r=\text { Estudante com situação de vínculo igual a "Formado" no curso } j \text { no ano } t \text {. } \\
F a l=\text { Estudante com situação de vínculo igual a "Falecido" no curso } j \text { no ano } t \text {. } \\
\sum_{i=1}^{n} I G_{i=j}^{T}=\text { Número total de ingressantes no curso j no ano T das bases de dados }\end{array}$ \\
\hline Unidade de medida & Porcentagem \\
\hline Periodicidade & Anual \\
\hline Fonte & Fórmula do INEP aplicado a dados do SIGA. \\
\hline Intepretação & $\begin{array}{l}\text { Percentual do número de estudantes que se formaram em determinado curso até o } \\
\text { dobro do prazo de integralização mínima deste dividido pelo número de } \\
\text { ingressantes desse curso no ano de ingresso considerado, subtraindo-se o número } \\
\text { de estudantes falecidos nesse período. }\end{array}$ \\
\hline
\end{tabular}

Fonte: Adaptado de INEP (2017).

Fonte: Adaptado de INEP (2017).

\section{Principais resultados}

Existem várias metodologias para calcular as "Taxas de evasão, diplomação e trancamento", desta forma, os resultados variam de acordo com a metodologia utilizada. Este método se baseou em algumas metodologias existentes: INEP (2017), Pereira, Zavala e Santos (2011) e Souza (2014), as quais realizam o acompanhamento longitudinal de alunos de acordo com ano de ingresso, durante o prazo de integralização ou período padrão previsto do curso. A Figura 2 descreve de forma geral a situação da turma ingressante de 2008 a 2017 até o final do ano corrente analisado, 2017.

Figura 2 - Taxas anuais longitudinais para UFMT por ano de ingresso (2008 - 2017)

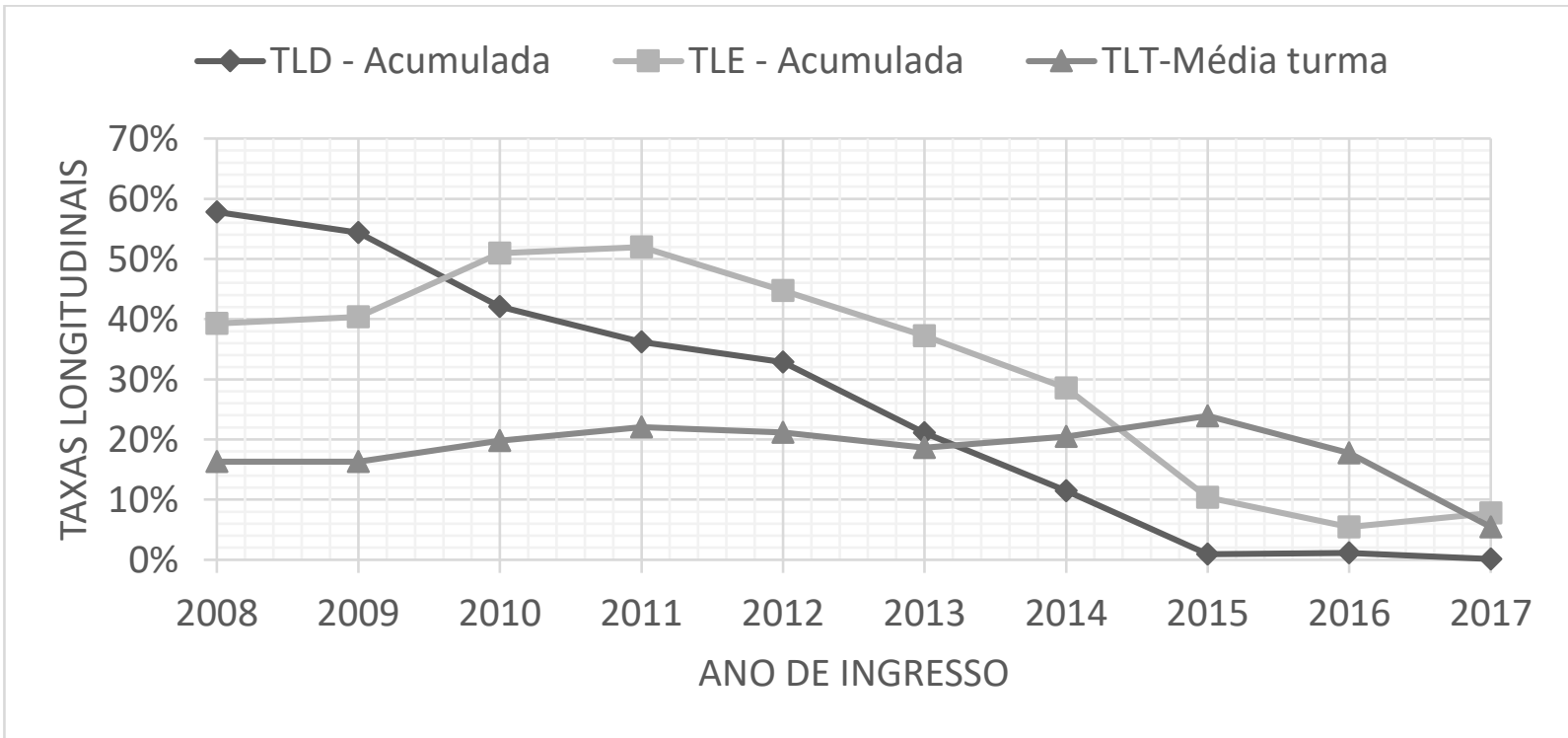

Fonte: Elaboração própria (2019). 
Nota-se na Figura 2 algumas alterações de padrões entre as turmas, principalmente a partir da turma que ingressou em 2010, quando a evasão supera a diplomação, seguindo nas turmas seguintes, até a turma de 2013 em que a taxa de diplomação e de trancamento se aproximam e a partir de 2014 a taxa de trancamento supera as demais taxas. Pode-se atribuir a mudança no padrão da evasão às diferenças que ocorreram na forma de ingresso, como a implantação do Sistema de Seleção Unificada (SISU) em que o estudante possui maior mobilidade entre cursos e instituições. Por outro lado, o padrão apresentado a partir de 2014 é reflexo das turmas que ingressaram recentemente, pois possuem um período menor de análise da trajetória, o que impacta também em taxas menores, pois muitos discentes ainda estão cursando as disciplinas e ainda não atingiram o tempo mínimo para integralização.

Diante da importância do prazo de integralização para o cálculo da taxa, esta variável também foi utilizada para calcular a média ponderada. Desta forma, a Tabela 2 relaciona a quantidade de cursos de graduação presencial incluídos no estudo de acordo com o prazo de integralização.

Tabela 2 - Quantidade de Cursos de acordo com prazo de integralização

\begin{tabular}{ccc}
\hline Prazo de Integralização & Quantidade de Cursos analisados & Percentual \\
\hline 6 anos & 3 & $3 \%$ \\
\hline 5 anos & 37 & $35 \%$ \\
\hline 4 anos & 66 & $62 \%$ \\
\hline Total & $\mathbf{1 0 6}$ & $\mathbf{1 0 0 \%}$ \\
\hline
\end{tabular}

Fonte: Elaboração própria (2019).

Conforme indicado na Tabela 2, 62\% dos cursos de graduação presencial da UFMT possuem o período mínimo de integralização de 4 anos. Apenas 3\% possuem o prazo de 6 anos. Considerando essa dispersão no tempo de integralização dos cursos, utilizou-se da média ponderada, utilizando como pesos o percentual de cursos por prazo de integralização, conforme Tabela 3.

Tabela 3 - Resultados médios do estudo da trajetória para UFMT Geral (2008 a 2017)

\begin{tabular}{ccccccc}
\hline Trajetória Média & \multicolumn{2}{c}{$\begin{array}{c}\text { Trajetória Long. } \\
\text { Diplomação }\end{array}$} & \multicolumn{2}{c}{$\begin{array}{c}\text { Trajetória Long. } \\
\text { Evasão }\end{array}$} & \multicolumn{2}{c}{$\begin{array}{c}\text { Trajetória Long. } \\
\text { Trancamento }\end{array}$} \\
\cline { 2 - 7 } & $\begin{array}{c}\text { Período } \\
\text { Mín. }\end{array}$ & $\begin{array}{c}\text { Período } \\
\text { Máx. }\end{array}$ & $\begin{array}{c}\text { Período } \\
\text { Mín. }\end{array}$ & $\begin{array}{c}\text { Período } \\
\text { Máx. }\end{array}$ & $\begin{array}{c}\text { Período } \\
\text { Mín. }\end{array}$ & $\begin{array}{c}\text { Período } \\
\text { Máx. }\end{array}$ \\
\hline $\begin{array}{c}\text { UFMT - Média } \\
\text { Ponderada* }\end{array}$ & $22 \%$ & $44 \%$ & $18 \%$ & $29 \%$ & $25 \%$ & $11 \%$ \\
\hline $\begin{array}{c}\text { UFMT - Média } \\
\text { Simples }\end{array}$ & $31 \%$ & $62 \%$ & $15 \%$ & $21 \%$ & $17 \%$ & $10 \%$ \\
\hline
\end{tabular}

Fonte: Elaboração própria, 2019.

*Ponderação pelo número de cursos de acordo com prazo de integralização conforme Tabela 2. 
Os resultados da média simples sugerem que dos ingressantes de 2008 a 2017, $31 \%$ dos discentes concluíram o curso no período mínimo e $62 \%$ concluíram no período máximo de integralização do curso. No entanto, quando se utiliza a média ponderada, estes índices se alteram para $22 \%$ e $44 \%$ respectivamente, o que tem mais relação com a realidade, levando em consideração a quantidade de cursos que apresentaram taxas semelhantes.

\subsection{Resultados por grau acadêmico}

Para facilitar a visualização e possibilitar análise detalhada, os dados foram agrupados por UFMT Geral, por Grau e por Turno de acordo com o prazo de integralização mínimo e máximo. Como havia uma taxa para cada categoria e para cada ano, estas foram ponderadas pelo número de cursos de acordo com o período de integralização, conforme descrito na metodologia. A Tabela 4 descreve o percentual de cursos de acordo com o grau e tempo de integralização.

Tabela 4 - Grau acadêmico dos cursos presenciais da UFMT, por tempo de integralização mínimo ajustado

\begin{tabular}{lcccr}
\hline Grau /Integralização & 4 ANOS & $\mathbf{5}$ ANOS & 6 ANOS & Total Geral \\
\hline Bacharelado & $48 \%$ & $48 \%$ & $4 \%$ & $100 \%$ \\
\hline Licenciatura & $94 \%$ & $6 \%$ & $0 \%$ & $100 \%$ \\
\hline Total UFMT & $\mathbf{6 2 \%}$ & $\mathbf{3 5 \%}$ & $\mathbf{3 \%} \%$ & $\mathbf{1 0 0 \%}$ \\
\hline
\end{tabular}

Fonte: Elaboração própria (2020).

Nota-se na Tabela 4 que a maioria dos cursos de licenciatura da instituição possuem a integralização padrão de 4 anos, já os bacharelados possuem o mesmo número de cursos com integralização de 4 e 5 anos. E a UFMT como um todo possui cerca de $62 \%$ de seus cursos com integralização de 4 anos. Com base nesse perfil, a Figura 3 descreve as taxas de diplomação, evasão e trancamento por grau.

Na Figura 3, os resultados da média ponderada sugerem que, dos ingressantes em cursos de licenciatura, de 2008 a 2017, 18\% dos discentes concluíram o curso no período mínimo e $32 \%$ no período máximo de integralização do curso. Para os cursos de bacharelado, $24 \%$ concluíram no período mínimo e $51 \%$ no período máximo de integralização. 
Figura 3 - Taxas longitudinais médias* para UFMT por Grau (2008 a 2017)

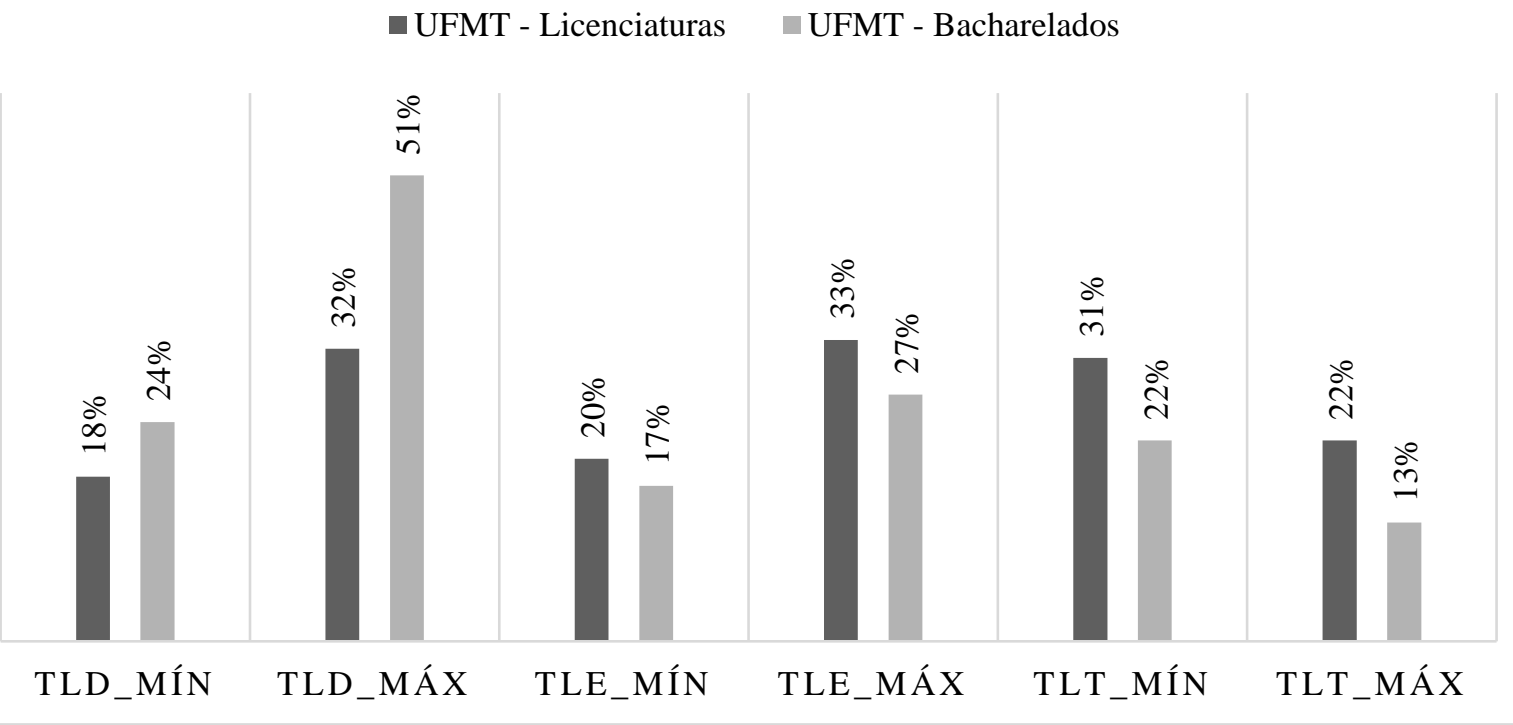

Fonte: Elaboração própria (2019).

* Ponderação pelo número de cursos de acordo com prazo de integralização.

Com relação à evasão, nas licenciaturas, $20 \%$ dos ingressantes, já haviam evadido decorrido o período mínimo do curso e $33 \%$ no período máximo, enquanto nos bacharelados $17 \%$ haviam evadido no período mínimo e $27 \%$ no período máximo. Com relação ao trancamento, nas licenciaturas $31 \%$ estavam trancados no ano em que se completava o período mínimo e $22 \%$ no ano do período máximo, já nos bacharelados, $22 \%$ estavam trancados no ano do período mínimo e $13 \%$ no ano do período máximo.

\subsection{Resultados por turno}

A Tabela 5 mostra a distribuição dos turnos dos cursos pelos seus prazos de integralização. Essas informações foram utilizadas para cálculo da média ponderada por turno, descrita na Figura 4.

Tabela 5 - Tempo mínimo de integralização ajustado por Turno dos cursos*

\begin{tabular}{ccccc}
\hline Turno & 4 ANOS & 5 ANOS & 6 ANOS & Total \\
\hline Integral & $34 \%$ & $60 \%$ & $6 \%$ & $100 \%$ \\
Matutino & $89 \%$ & $11 \%$ & $0 \%$ & $100 \%$ \\
Noturno & $89 \%$ & $11 \%$ & $0 \%$ & $100 \%$ \\
Vespertino & $80 \%$ & $20 \%$ & $0 \%$ & $100 \%$ \\
\hline Total Geral & $\mathbf{6 6 \%}$ & $\mathbf{3 1 \%}$ & $\mathbf{2 \%}$ & $\mathbf{1 0 0 \%}$ \\
\hline
\end{tabular}

Fonte: Elaboração própria (2019).

* Os cursos foram agrupados conforme seu turno de oferta e, quando um mesmo curso é ofertado em mais de um turno, foi contabilizado mais de uma vez. 
A Tabela 5 mostra que a maioria dos cursos ofertados no período integral tem o prazo de integralização de 5 anos, principalmente em virtude dos cursos da área de engenharia, enquanto os cursos ofertados nos períodos matutino, noturno e vespertino são normalmente integralizados em 4 (quatro) anos. Diante desta perspectiva, a Figura 4 apresenta as taxas longitudinais médias de diplomação, evasão e trancamento por turno.

Figura 4 - Taxas longitudinais médias para UFMT por Turno (2008 a 2017)

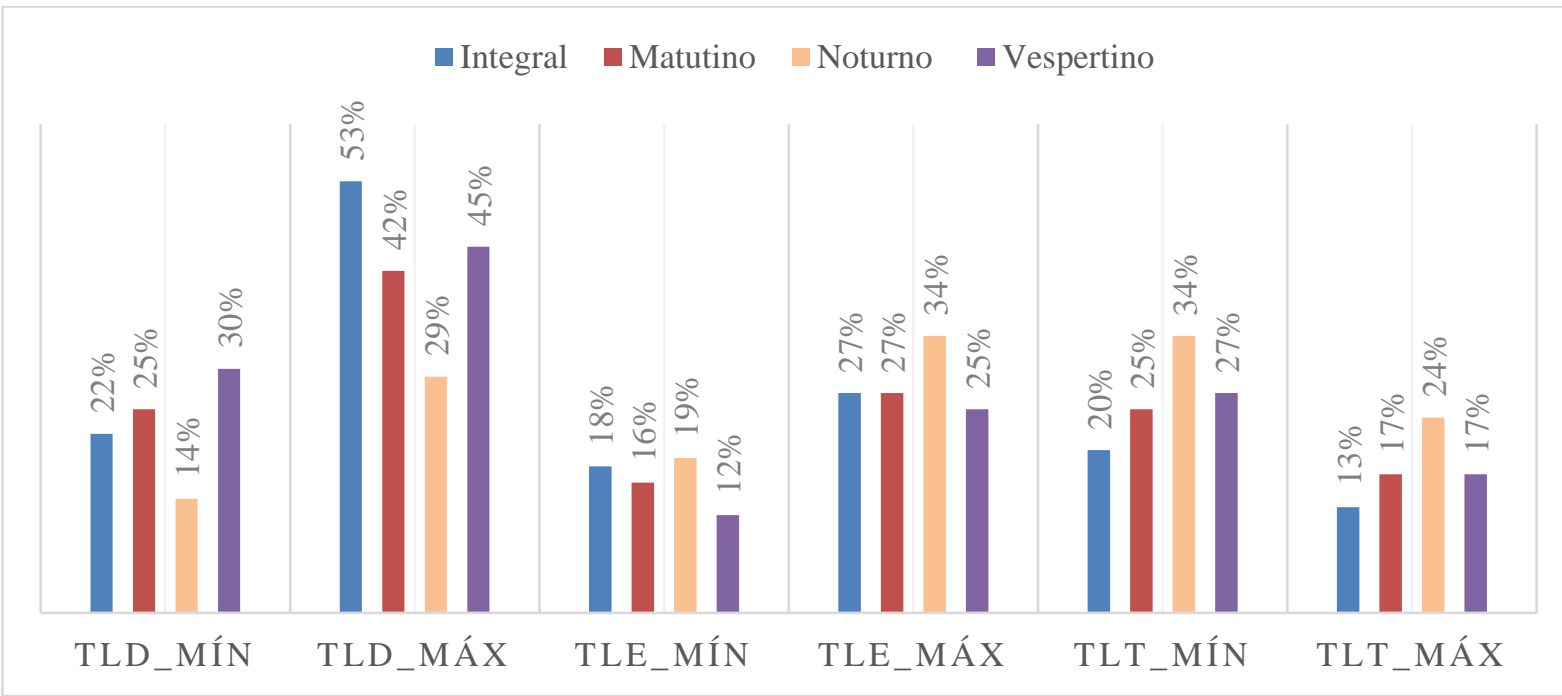

Fonte: Elaboração própria (2019).

Ponderação pelo número de cursos de acordo com prazo de integralização.

A Figura 4 mostra que os cursos da instituição com turno vespertino tiveram maior taxa de diplomação no período mínimo, enquanto os cursos com turno integral tiveram a maior taxa de diplomação no período máximo. Para as taxas de trancamento e evasão os cursos com turno noturno tiveram a maior taxa tanto no período mínimo, quanto no período máximo.

\section{Comparação entre as taxas de sucesso}

A definição e medição do termo "sucesso acadêmico" é necessariamente complexa e ampla. Segundo York, Gibson e Susan (2015) o sucesso acadêmico é composto de seis componentes: desempenho acadêmico, satisfação, aquisição de habilidades e competências, persistência, alcance de objetivos de aprendizagem e sucesso na carreira. $\mathrm{O}$ termo vem sendo frequentemente mal utilizado na pesquisa educacional para encapsular todos os resultados geralmente desejados. Apesar dos relatórios que defendem visões mais detalhadas do termo sucesso (KUH et al., 2006), a maior parte dos pesquisadores publicados continua a medir o sucesso acadêmico como desempenho acadêmico. 
Desta forma, após conhecer as taxas longitudinais da instituição para o período de 2008 a 2017, pesquisou-se algumas taxas já publicadas para a instituição para contrapor os resultados e analisar as diferenças que foram encontradas. A Tabela 6 descreve algumas taxas calculadas e publicadas para a instituição.

Tabela 6 - Evolução de Taxas de Sucesso para UFMT

\begin{tabular}{c|c|c|c|c}
\hline Taxas & $\mathbf{2 0 1 4}$ & $\mathbf{2 0 1 5}$ & $\mathbf{2 0 1 6}$ & $\mathbf{2 0 1 7}$ \\
\hline Taxa de Sucesso na Graduação (TSG-TCU) & - & $45 \%$ & $44 \%$ & $41 \%$ \\
\hline Taxa de Sucesso do INEP (TAS-INEP) & $50 \%$ & $43 \%$ & $39 \%$ & $40 \%$ \\
\hline Taxa de Eficiência (TEF-INEP) & $18 \%$ & $18 \%$ & $17 \%$ & $19 \%$ \\
\hline
\end{tabular}

Fonte: Elaboração própria (2019). Dados: Censo da Educação Superior (2018); SIGA (2018); INEP (2017).

A Tabela 6 mostra que as Taxas de Sucesso do TCU e do INEP tiveram valores ligeiramente distintos, em contrapartida, a Taxa de Eficiência mostrou-se bem distinta em todo o período analisado. Essas diferenças advêm principalmente por conta do período até a conclusão analisado, ou seja, se é considerado um período mínimo, apenas com ingressantes do ano em questão, como a TEF, o valor é inferior. Na taxa do TCU é considerado o período mínimo ou padrão do curso, no entanto, consideram todos os formados do ano, podendo ser estudantes que ingressaram em períodos distintos do mínimo. Na taxa de sucesso do INEP são considerados apenas os concluintes que ingressaram durante o prazo máximo do curso. No entanto, há alguns casos em que o estudante pode continuar estudando, mesmo após o período máximo, no caso da UFMT, esse período corresponde a 1,5 vezes o período mínimo.

Após análise dos métodos e resultados, considera-se que o período máximo deveria ser considerado, pois demorar para diplomar, não significa insucesso. Nota-se que a taxas com mesmo objetivo de medir o sucesso estudantil por meio dos concluintes podem demonstrar valores bem distintos, sendo que a principal alteração nas fórmulas tem relação com o período considerado. Desta forma, é crucial conhecer os métodos, o que consideram e o que não medem.

\section{Considerações finais}

As taxas e indicadores utilizados na Educação Superior são fundamentais para conhecer a realidade das instituições, no entanto, deve-se frisar a parcela da realidade que conseguem mostrar, ou seja, a maioria destes quando muito simplificados, escondem alguns aspectos que poderiam ser fundamentais para o tipo de política e resultados que se almeja alcançar.

Diante das taxas longitudinais calculadas nesta pesquisa, a saber a Taxa Longitudinal de Diplomação (TLD), a Taxa Longitudinal de Evasão (TLE) e a Taxa Longitudinal de 
Trancamento (TLT), foi possível conhecer profundamente alguns aspectos da instituição relevantes para o direcionamento de políticas e ações. A maior limitação destas taxas consiste na dificuldade de manipulação dos dados diante da grande quantidade de informações, no entanto, possibilitou um profundo conhecimento de várias interfaces da instituição, antes desconhecidas.

Destaca-se o papel importante da inclusão do prazo de integralização do curso no cálculo, tanto o prazo padrão aqui descrito como prazo mínimo quanto o prazo máximo. Ao alternar esta variável, foi possível identificar taxas bem discrepantes, tanto para diplomação quanto para evasão. Para o trancamento, notou-se também ligeira diferença. Neste sentido, considerar apenas o prazo mínimo pode afetar negativamente os indicadores e fornecer valores que podem não condizer com a realidade de sucesso do curso, e consequentemente da instituição. Desta forma, analisar os alunos em um período maior é essencial para conhecer a realidade institucional.

Notou-se que os alunos da instituição estudada, muitas vezes categorizados como "não sucesso", apenas estão demorando um pouco mais para chegar ao "sucesso". Ou seja, nota-se que a maioria dos discentes estão demorando mais para se formar. Outro ponto é a questão da análise por turmas separadamente, notou-se que principalmente as turmas a partir de 2010 obtiveram maiores taxas de evasão já nos anos iniciais, assim como trancamento. Esse resultado é percebido também em outras instituições, diante da alteração da forma de ingresso (SISU) ter sido implantada em 2010, o que proporcionou maior mobilidade.

Quando as taxas foram analisadas por alguma categoria, também resultou em diferenças, como exemplo, as diferenças encontradas entre graus, no qual os bacharelados tiveram taxas ligeiramente mais promissoras. Quando analisado por turnos, o noturno apresentou taxas inferiores aos demais.

Para além das comparações possibilitadas pelo estudo, sugere-se alguns pontos que poderiam aprimorar a correta captação do sucesso dos alunos: a) utilização do período máximo de integralização, principalmente para os cursos novos que demandam mais tempo para consolidação; b) inserção de um componente de correção indicando "ingressantes efetivos", no qual seriam excluídos aqueles que pediram algum tipo de transferência no primeiro ano ou semestre, diante da alta mobilidade de estudantes entre os cursos e instituições federais. 


\section{Referências}

BAGGI, Cristiane Aparecida dos Santos; LOPES, Doraci Alves. Evasão e avaliação institucional no ensino superior: uma discussão bibliográfica. Avaliação, Campinas; Sorocaba, v. 16, n. 2, p. 355-374, 2011. Disponível em: https://www.scielo.br/j/aval/a/RRGrQckrsd9CRGgKy4zkHXq/?lang=pt. Acesso em: 20 maio 2020.

BRASIL. Ministério da Educação. Secretaria de Educação Superior. Comissão especial de estudos sobre a evasão nas universidades públicas brasileiras. Brasília: ANDIFES/ABRUEM/SESU/MEC, 1997.

BRASIL. Lei $N^{\circ} 13.005$, de 25 de junho de 2014. Aprova o Plano Nacional de Educação PNE, e dá outras providências. Diário Oficial da União, Brasília, 26 jun. 2014. Disponível em: https://www2.camara.leg.br/legin/fed/lei/2014/lei-13005-25-junho-2014-778970publicacaooriginal-144468-pl.html. Acesso em: 22 maio 2020.

CABELLO, Andrea Felippe et al. Evasão no ensino superior: qual metodologia adotar? Uma análise sobre o efeito de diferentes metodologias para a identificação dos índices de evasão no ensino superior brasileiro. In: COLÓQUIO INTERNACIONAL DE GESTIÓN UNIVERSITARIA, 18., 2018, Curitiba. Anais [...]. Curitiba: UTPL, 2018. Disponível em: https://repositorio.ufsc.br/bitstream/handle/123456789/191468/101_00150.pdf?sequence=1\&i sAllowed=y. Acesso em: 25 fev. 2020.

CARDOSO, Claudete Batista. Efeitos da política de cotas na Universidade de Brasília: uma análise do rendimento e da evasão. 2008. Dissertação (Mestrado em Educação) Universidade de Brasília, Brasília, 2008. Disponível em:

https://repositorio.unb.br/bitstream/10482/1891/1/2008_ClaudeteBatistaCardoso.pdf. Acesso em: 25 abr. 2020.

CAVALCANTE, Sueli Maria de Araújo. Avaliação da eficiência acadêmica dos cursos de graduação da Universidade Federal do Ceará (UFC): utilização de indicadores de desempenho como elemento estratégico da gestão. 2011. Tese (Doutorado) - Universidade Federal do Ceará, Fortaleza, 2011. Disponível em:

http://www.repositorio.ufc.br/bitstream/riufc/6641/1/2011_tese_smacavalcante.pdf. Acesso em: 26 jun. 2020.

CUNHA, Aparecida Miranda; TUNES, Elizabeth; SILVA, Roberto Ribeiro da. Evasão do curso de Química da Universidade de Brasília: a interpretação do aluno evadido. Química Nova, São Paulo, v. 24, n. 2, p. 262-280, mar./abr. 2001. Disponível em:

https://www.scielo.br/j/qn/a/N67XK4g46ckwYKq7bBFhVvH/?lang=pt\#. Acesso em: 25 jul. 2020.

DURSO, Samuel de Oliveira; CUNHA, Jacqueline Veneroso Alves da. Determinant factors for undergraduate student's dropout in an accounting studies department of a brazilian public university. Educação em Revista, Belo Horizonte, v. 34, 2018. Disponível em:

https://doi.org/http://dx.doi.org/10.1590/0102-4698186332. Acesso em: 18 abr. 2019.

FREIRE, Fátima de Souza; CRISÓSTOMO, Vicente Lima; CASTRO, Juscelino Emanoel Gomes de. Análise do Desempenho Acadêmico e Indicadores de Gestão das IFES. Revista 
Produção On Line, Florianópolis, v. 20, n. 4, p. 25, 2007. Disponível em:

https://doi.org/https://doi.org/10.14488/1676-1901.v7i4.57. Acesso em: 18 abr. 2019.

GAIOSO, Natalicia Pacheco de Lacerda. O fenômeno da evasão escolar na educação superior no Brasil. 2005. Dissertação (Mestrado em Educação) - Programa de PósGraduação em Educação da Universidade Católica de Brasília, Brasília, 2005.

GERAB, Fábio. Cálculo da evasão e do índice de titulação em cursos usando uma abordagem probabilística. In: CONGRESSO BRASILEIRO DE EDUCAÇÃO EM ENGENHARIA, 44., Natal, 2016. Disponível em:

https://www.researchgate.net/profile/fabio_gerab/publication/311664935_calculo_da_evasao_ e_do_indice_de_titulacao_em_cursos_usando_uma_abordagem_probabilistica/links/5852c08 508ae7d33e01aadf1/calculo-da-evasao-e-do-indice-de-titulacao-em-cursos-usando-umaabordagem-probabilistica.pdf. Acesso em: 30 abr. 2020.

INEP - INSTITUTO NACIONAL DE ESTUDOS E PESQUISAS EDUCACIONAIS ANÍSIO TEIXEIRA - INEP. Diretoria de Estatísticas Educacionais (DEED). Metodologia de Cálculo dos indicadores de fluxo da educação superior. Brasília: INEP, 2017. Disponível em:

http://download.inep.gov.br/informacoes_estatisticas/indicadores_educacionais/2017/metodol ogia_indicadores_trajetoria_curso.pdf. Acesso em: 25 out. 2019.

INEP - INSTITUTO NACIONAL DE ESTUDOS E PESQUISAS EDUCACIONAIS ANÍSIO TEIXEIRA. Sinopses estatísticas da educação superior 2016 - Graduação. Brasília: INEP, 2018. Disponível em: http://inep.gov.br/sinopses-estatisticas-da-educacaosuperior. Acesso em: 25 nov. 2020.

KUH, George et al. What matters to student success: a review of the literature. Commissioned report for the National Symposium on Postsecondary Student Success: Spearheading a Dialog on Student Success. Washington, DC: National Postsecondary Education Cooperative, 2006. Disponível em: https://nces.ed.gov/npec/pdf/kuh_team_report.pdf. Acesso em: 15 abr. 2020.

LIMA JUNIOR, Paulo et al. Taxas longitudinais de retenção e evasão: uma metodologia para estudo da trajetória dos estudantes na educação superior. Ensaio: Avaliação e Políticas Públicas em Educação, Rio de Janeiro, v. 27, n. 102, p. 157-178, 2019. Disponível em: https://doi.org/10.1590/s0104-40362018002701431. Acesso em: 15 mar. 2020.

MASSI, Luciana; VILLANI, Alberto. Um caso de contra tendência: baixa evasão na licenciatura em química explicada pelas disposições e integrações. Educação e Pesquisa, São Paulo, v. 41, n. 4, p.975-992, dez. 2015. Disponível em:

https://repositorio.unesp.br/handle/11449/157783. Acesso em: 23 abr. 2020.

PEREIRA, Rosângela Saldanha; ZAVALA, Arturo Alejandro Zavala; SANTOS, Antônio César. Evasão na Universidade Federal de Mato Grosso. Revista de Estudos Sociais, Cuiabá, v. 13, n. 26, 2011.

POLYDORO, Soely Aparecida Jorge. O trancamento de matrícula na trajetória acadêmica no universitário: condições de saída e de retorno à instituição. 2000. Tese (Doutorado em Educação) - Universidade Estadual de Campinas, Campinas, 2000. 
RISTOFF, Dilvo. Universidade em foco: reflexões sobre a educação superior. Florianópolis: Insular, 1999.

SANTOS JUNIOR, José da Silva; REAL, Giselle Cristina Martins. A evasão na educação superior: o estado da arte das pesquisas no Brasil a partir de 1990. Avaliação, Campinas; Sorocaba, v. 22, n. 2, p. 385-402, 2017. Disponível em: https://doi.org/10.1590/s141440772017000200007. Acesso em: 15 abr. 2019.

SILVA FILHO, Roberto Leal Lobo et al. A evasão no ensino superior brasileiro. Cadernos de Pesquisa, São Paulo, v. 37, n. 132, p. 641-659, dez. 2007. Disponível em: https://www.scielo.br/j/cp/a/x44X6CZfd7hqF5vFNnHhVWg/?lang=pt. Acesso em: 7 fev. 2019.

SILVA FILHO, Roberto Leal Lobo; LOBO, Maria Beatriz de Carvalho Melo. Como a mudança na metodologia do INEP altera o cálculo da evasão. Mogi das Cruzes: Instituto Lobo, 2012.

SILVA, César Augusto Tibúrcio; MORGAN, Beatriz Fátima; COSTA, Patrícia de Souza. Desenvolvimento e aplicação de uma metodologia para cálculo do custo-aluno de instituições públicas de ensino superior: um estudo de caso. Revista de Administração

Pública, Rio de Janeiro, v. 38, n. 2, p. 243-259, 2004. Disponível em: https://bibliotecadigital.fgv.br/ojs/index.php/rap/article/view/6536. Acesso em: 17 abr. 2020.

SILVA, Maria das Graças Martins da; VELOSO, Tereza Christina Mertens Aguiar. Acesso nas políticas da educação superior: dimensões e indicadores em questão. Avaliação, Campinas; Sorocaba, v. 18, n. 3, p. 727-747, 2013. Disponível em:

https://www.scielo.br/j/aval/a/S7nJrFjwknrbSPgxQMfXZwf/abstract/?lang=pt. Acesso em: 17 abr. 2020.

SOUZA, Irineu Manoel de. Causas da evasão nos cursos de graduação da Universidade Federal de Santa Catarina. 2014. Dissertação (Mestrado) - Universidade Federal de Santa Catarina, Florianópolis, 2014. Disponível em:

https://repositorio.ufsc.br/handle/123456789/81300. Acesso em: 19 ago. 2020.

TRIBUNAL DE CONTAS DA UNIÃO - TCU. Orientações para o cálculo dos indicadores de gestão. DECISÃO Nº 408/2002-PLENÁRIO e ACÓRDÃOS N 1043/2006 e N 2167/2006 - PLENÁRIO TRIBUNAL DE CONTAS DA UNIÃO. 2010. Disponível em: https://www2.ufjf.br/diavi/wpcontent/uploads/sites/31/2021/05/Manual_2442932_Orientacoes_para_o_calculo_dos_Indica dores_de_Gestao_TCU_CGU_SESU_2010.pdf. Acesso em: 20 abr. 2020.

VELOSO, Tereza Christina Mertens Aguiar; ALMEIDA, Edson Pacheco de. Evasão nos cursos de graduação da Universidade Federal de Mato Grosso, campus universitário de Cuiabá: um processo de exclusão. In: REUNIÃO ANUAL DA ANPEd, 24., 2001, CaxambuMG. Anais eletrônicos. Caxambu: ANPEd, 2001.

YORK, Travis; GIBSON, Charles; SUSAN, Rankin. Defining and measuring academic success. Practical Assessment, Research \& Evaluation, Washington, DC, v. 20, n. 5, p. 120, mar. 2015. Disponível em: 
https://scholarworks.umass.edu/cgi/viewcontent.cgi?article=1260\&context=pare. Acesso em: 26 set. 2019. 